previous note: $.64, .8$, г.o, г.3, г.6, 2. $, 2.6,3.2 \mathrm{~mm}$. The present larvae exhibited .65,.8, 1.3, 2.2, 3.3, thus omitting every alternate stage after the second. In my larva formerly described, the last four measurements of the normal series were actually observed, and the larva must have had as many as seven stages, omitting normal iii, or perhaps eight, including iii. It is probable that in Dr. Packard's example but two stages were omitted, although we cannot say which, as he does not give us measurements of the head. Miss Soule's was doubtless the same as my last.

I will not describe the egg and larval stages in detail, as there is but little to add to the accounts already published. The arrangement of the hairs may be mentioned, as it is decidedly peculiar.

There is no primitive first stage. On hatching, the hairs are abundant, arising from low, flat granular wart areas, whose position is most difficult to determine positively, as they are obscured by the hairs, and when the latter are removed are difficult to distinguish, being merely concolorous granular areas. After repeated observation, I believe the accompanying cut represents
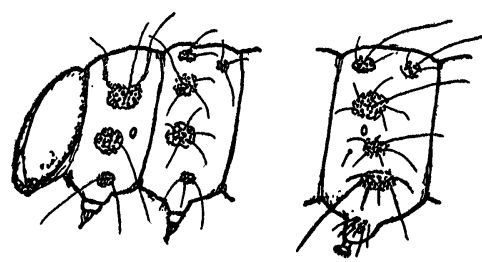

Apatelodes torrefacta.

their arrangement correctly. The hairs are represented as partly removed. On the abdomen i, ii, iii normal, iv very large and $v$ small, vi large, the base of the leg hairy. On the last two thoracic segments three warts above the stigmatal wart, the middle one moved back out of line with the others, stigmatal and subventral warts normal. I could not determine the exact period at which the secondary hairs appeared; probably in stage ii, though in my notes I state " secondary hairs not seen, if present can not distinguish them from those bending over from the warts." In the last stage, the secondary coating is well developed.

\section{DEIDAMIA INSCRJPTA.}

On June iI I found two larvae on a grapevine, and a few days later five more on Ampelopsis quinquefolia. The record is taken from the first two.

Length $\frac{3}{4}$ inch. Head round, green, with 4 very faint yellow face-lines. Body bright green, transversely striated with opaque yellow. 3rd and $4^{\text {th }}$ segments very slightly enlarged, too slightly to be noticed except by an entomologist. From the outer facelines to the caudal horn extended subdorsal lines of yellow, edged above with dark green. A stigmatal yellow edge ran from the first segment into the first oblique on each side. There were eight yellow obliques the eighth being under the caudal horn, and running backward from that. Anal shield edged with yellow. Caudal horn long, slender, straight, black, rough. Feet yellow, props green, venter plain green. 
Fune 15. Moulted. $I_{8}^{1}$ inches long. As before except that the body below the subdorsal lines was thickly granulated with yellow; the caudal horn became green beneath, yellow on the sides, with a black line on the upper side and a black band just below the green tip. The spiracles showed as two blue black lines with white between and a yellowish dot at each end. When disturbed the larvae twitched and jerked from side to side like abbottii and nessus.

Fune 2o. Moulted. $\mathrm{I} \frac{1}{2}$ inches long. As before, except a blue green dorsal line extended from second segment to the horn, the first segment being smoother and greener than any other; and the caudal horn had become pink above and beneath, yellow on the sides and tip, slightly rough. The larvae rested with the head and first three segments thrown back over the abdominal segments, like myron.

Fune 25. The larvae were $2 \frac{1}{8}$ inches long. The subdorsal lines had faded, except on the first three and the preanal segments, and had wholly disappeared from the 4 th, 5 th, and 6 th segments. The obliques were much less conspicuous. The caudal horn was shining yellow at the upper end, rough and pink below, short, stout, almost triangular when seen from the front. It was very small in proportion to the size of the larva. The yellow face-lines nearest the median suture could hardly be seen.

Fune 26. They stopped eating, and their heads and backs turned deep dull pink.

Fuly $r$. Pupated well, the pupae being very strongly marked.

The seven larvae found varied somewhat in color, some being of a very white green instead of the deep yellow green of the first two. Some had but seven obliques instead of eight, and two lost the eighth oblique at the last moult. Three or four had caudal horns green and yellow instead of pink and yellow. Two or three grew to a length of $2 \frac{3}{8}$ inches.

Caroline G. Soule.

Brookline, Mass.

\section{SCHISTOCERCA AMERICANA IN NEW ENGLAND.}

On Oct. Ist, 1883 , I found this species at Wollaston, Mass. No record has ever been made of the capture, for at the time I was not interested in Orthoptera, and did not know the identity of the specimens. It was only recently that an examination by Mr. A. P. Morse of material collected by me years ago revealed the fact of its having been taken at that time.

It was tolerably abundant in one spot on the beach, where it was found among the tall grass below high-tide mark. Not knowing its value at the time, I failed to take more than a single specimen.

A search in the same locality this year failed to reveal any trace of its present existence there, so that it seems probable that it was by some means brought there and gained a temporary foothold. As the locality has been recently built upon to some extent it may have been exterminated by this means.

Frank H. Sprague.

\section{THE INSECT COLLECTION OF THE}

\section{U. S. NATIONAL MUSEUM.}

The staff of the Department of Insects of the U. S. National Museum has been reorganized as a result of the sad death of the former Honorary Curator, Professor C. V. Riley.

The reorganization has been effected by the appointment of Mr. L. O. Howard, Entomologist of the U. S. Department of Agriculture, to the position of Honorary Curator of the Department of Insects; of $\mathrm{Mr}$. Wm. H. Ashmead to the position of Custodian of Hymenoptera; and Mr. D. W. Coquillett to the position of Custodian of Diptera. All museum custodians are honorary officers. Mr. M. L. Linell will remain as general assistant to the Honorary Curator.

The Department is at present in excellent working condition. It contains a very great 

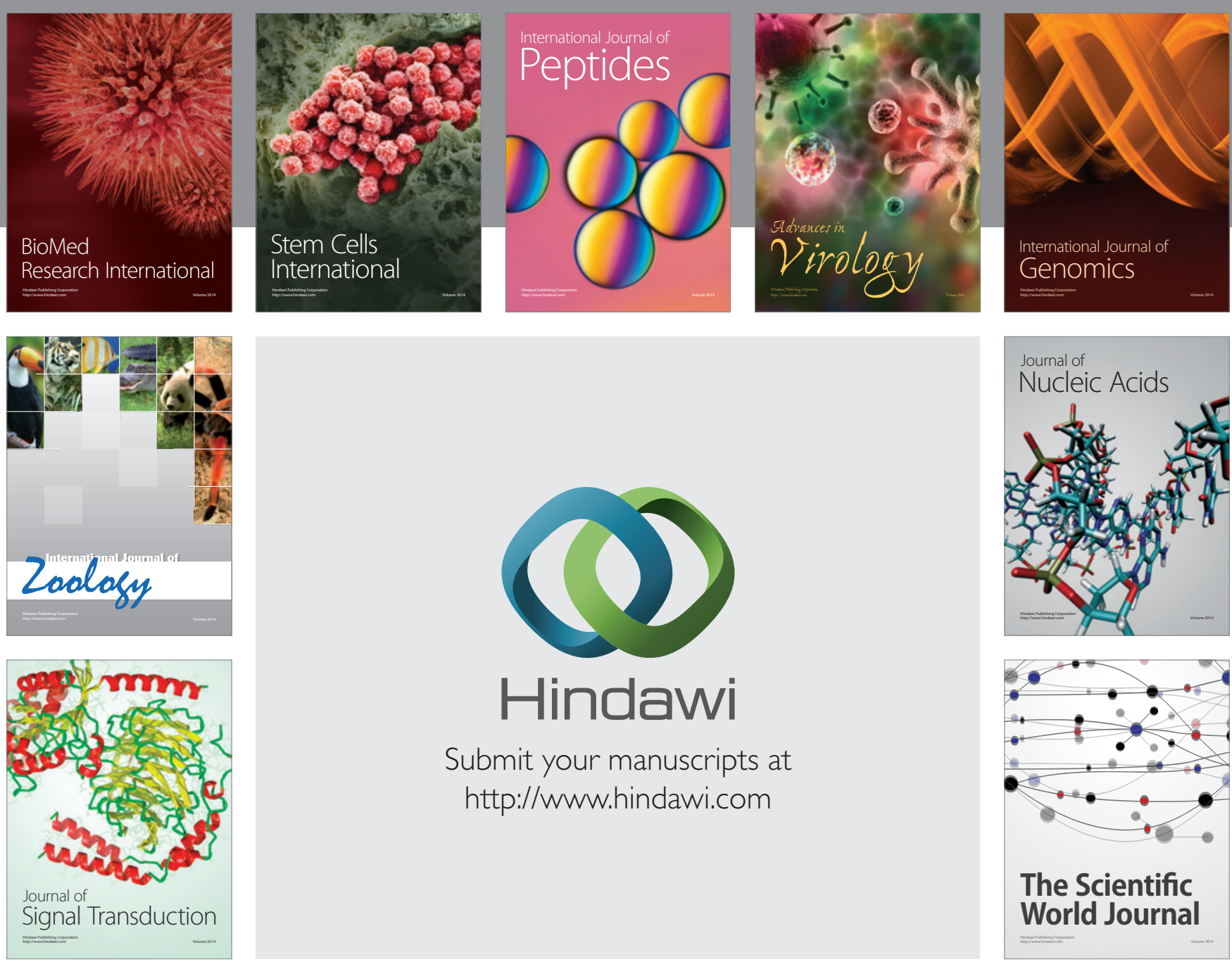

Submit your manuscripts at

http://www.hindawi.com
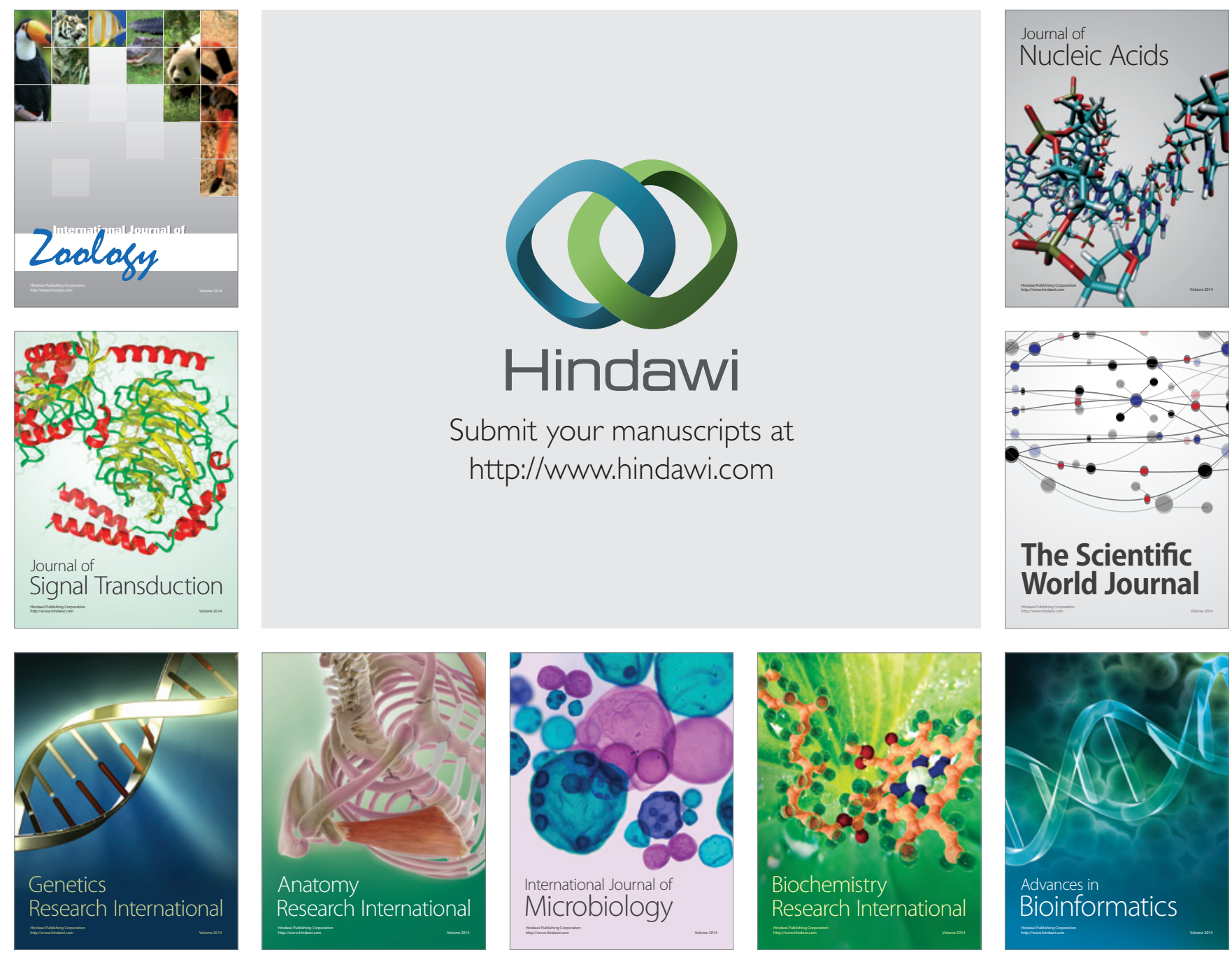

The Scientific World Journal
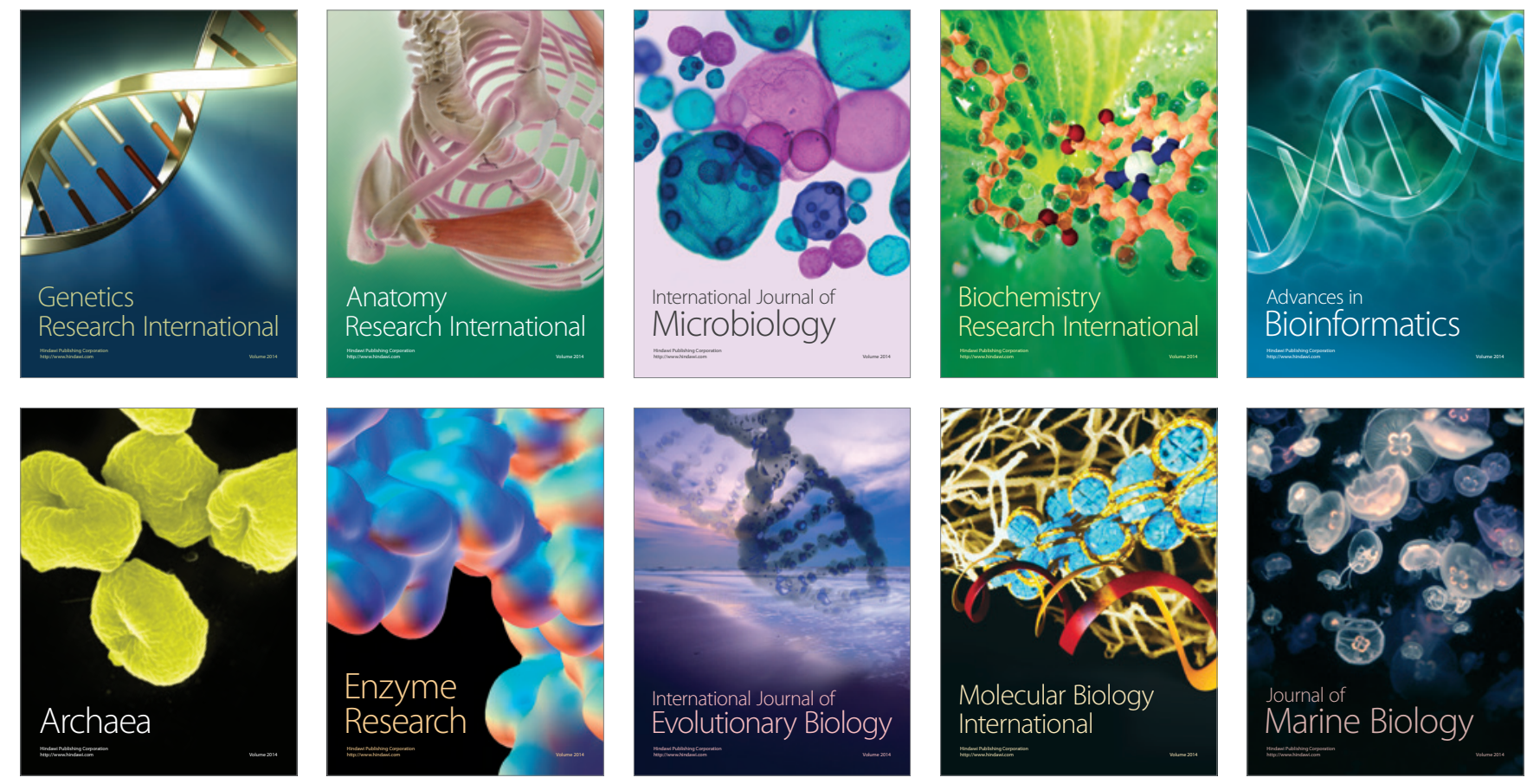